\title{
Implementation of European Society of Gastrointestinal Endoscopy (ESGE) recommendations for small-bowel capsule endoscopy into clinical practice: Results of an official ESGE survey
}

Authors

Lazaros-Dimitrios Lazaridis ${ }^{1,}{ }^{*}$, Georgios Tziatzios ${ }^{1, *} \odot$, Ervin Toth ${ }^{2} \odot$, Hanneke Beaumont ${ }^{3}$, Xavier Dray ${ }^{4}$, Rami Eliakim $^{5}$, Pierre Ellul ${ }^{6}$, Ignacio Fernandez-Urien ${ }^{7}$, Martin Keuchel ${ }^{8}$, Simon Panter ${ }^{9}$, Emanuele Rondonotti ${ }^{10}$, Bruno Rosa $^{11}$, Cristiano Spada ${ }^{12}$, Rodrigo Jover ${ }^{13}$, Pradeep Bhandari ${ }^{14}$, Konstantinos Triantafyllou ${ }^{1}$, Anastasios Koulaouzidis ${ }^{15}$, on behalf of the ESGE Research Committee Small-Bowel Working Group

Institutions

1 Hepatogastroenterology Unit, Second Department of Internal Medicine - Propaedeutic, Medical School, National and Kapodistrian University of Athens, Attikon University General Hospital, Athens, Greece

2 Department of Gastroenterology, Skåne University Hospital, Malmö, Lund University, Sweden

3 Department of Gastroenterology, Amsterdam University Medical Center, location VUMC, Amsterdam, The Netherlands

4 Sorbonne University, Center for Digestive Endoscopy, Hôpital Saint Antoine, APHP, Paris, France

5 Sheba Medical Center, Department of Gastroenterology, Sackler School of Medicine, Tel-Aviv University, Tel-Aviv, Israel

6 Division of Gastroenterology, Mater Dei Hospital, Malta

7 Complejo Hospitalario de Navarra, Pamplona, Spain

8 Clinic for Internal Medicine, Agaplesion Bethesda Krankenhaus Bergedorf, Hamburg, Germany

9 Department of Gastroenterology, South Tyneside District Hospital, South Tyneside and Sunderland NHS Foundation Trust, South Shields, UK

10 Gastroenterology Unit, Valduce Hospital, Como, Italy

11 Gastroenterology Department, Hospital da Senhora da Oliveira, Guimarães, Portugal

12 Digestive Endoscopy Unit and Gastroenterology, Fondazione Poliambulanza, Brescia, Italy

13 Servicio de Medicina Digestiva. Hospital General Universitario de Alicante, Instituto de Investigación Sanitaria ISABIAL, Alicante, Spain

14 Department of Gastroenterology, Queen Alexandra Hospital Portsmouth, Portsmouth, UK

15 Pomeranian Medical University, Department of Social Medicine and Public Health, Faculty of Health Science, Szczecin, Poland published online 28.7.2021

Bibliography

Endoscopy 2021; 53: 970-980

DOI 10.1055/a-1541-2938

ISSN 0013-726X

(C) 2021. European Society of Gastrointestinal Endoscopy

All rights reserved.

This article is published by Thieme.

Georg Thieme Verlag KG, Rüdigerstraße 14,

70469 Stuttgart, Germany

丹 Table 1s

Supplementary material is available under

https://doi.org/10.1055/a-1541-2938

Corresponding author

Konstantinos Triantafyllou, MD PhD, Hepatogastroenterology Unit, Second Department of Internal Medicine -

Propaedeutic, Medical School, National and Kapodistrian University of Athens, Attikon University General Hospital, 1

Rimini Street, 12462 Athens, Greece

Fax: +30-210-5326454

ktriant@med.uoa.gr

\section{ABSTRACT}

Background We aimed to document international practices in small-bowel capsule endoscopy (SBCE), measuring adherence to European Society of Gastrointestinal Endoscopy (ESGE) technical and clinical recommendations.

Methods Participants reached through the ESGE contact list completed a 52-item web-based survey.

Results 217 responded from 47 countries (176 and 41, respectively, from countries with or without a national society affiliated to ESGE). Of respondents, $45 \%$ had undergone formal SBCE training. Among SBCE procedures, $91 \%$

\footnotetext{
* Joint first authors
} 
were performed with an ESGE recommended indication, obscure gastrointestinal bleeding (OGIB), iron-deficiency anemia (IDA), and suspected/established Crohn's disease being the commonest and with higher rates of positive findings ( $49.4 \%, 38.2 \%$ and $53.5 \%$, respectively). A watchful waiting strategy after a negative SBCE for OGIB or IDA was preferred by $46.7 \%$ and $70.3 \%$, respectively. SBCE was a second-line exam for evaluation of extent of new Crohn's disease for $62.2 \%$ of respondents. Endoscopists adhered to varying extents to ESGE technical recommendations regarding bowel preparation (>60\%), use in those with pacemaker holders (62.5\%), patency capsule use (51.2\%), and use of a validated scale for bowel preparation assessment $(13.3 \%)$. Of the respondents, $67 \%$ read and interpreted the exams themselves and $84 \%$ classified exams findings as relevant or irrelevant. Two thirds anticipated future increase in SBCE demand. Inability to obtain tissue (78.3\%) and high cost $(68.1 \%)$ were regarded as the main limitations, and implementation of artificial intelligence as the top development priority (56.2\%).

Conclusions To some extent, endoscopists follow ESGE guidelines on using SBCE in clinical practice. However, variations in practice have been identified, whose implications require further evaluation.

\section{Introduction}

Small-bowel capsule endoscopy (SBCE) is the first-line investigatory modality for suspected small-bowel bleeding, but it can also contribute to the investigation of Crohn's disease (CD), refractory celiac disease, and small-bowel tumors [1-5]. Although SBCE is technically sophisticated, its quality depends on the distinct protocols applied before the procedure (bowel preparation), intraprocedurally (SBCE reading), and post-procedurally (reporting, evaluation of capsule egestion). These can reflect regional and/or organizational financial pressures, resulting in considerable variation in SBCE practice among endoscopic departments [6].

To address this issue, the European Society of Gastrointestinal Endoscopy (ESGE) has published evidence-based clinical and technical reviews, listing a series of fundamental recommendations that should be followed to enhance SBCE quality $[3,7]$. Despite their availability, it remains unclear whether these guidelines have been incorporated into clinical practice. Previous national surveys [8-11] have tried to answer this question, but there are no data addressing this issue at an international level.

In this context, the current survey aimed to document routine practices during SBCE endoscopy, both in countries with a national endoscopy society affiliated to ESGE and in those without (henceforth respectively referred to as "ESGE countries" and "non-ESGE countries"), and to investigate the potential influence of the ESGE guidelines on practice.

\section{Methods}

\section{Study design}

We carried out a cross-sectional web survey examining the current status of SBCE practices among endoscopists with a specialty interest in the examination, in ESGE and non-ESGE countries from July to November 2019.

\section{Development and content of survey instrument}

The ESGE Research Committee Small-Bowel Working Group convened a researcher team (K.T., A.K., and E.T.) with expertise in SBCE endoscopy to develop a dedicated electronic survey.
The commercially available version of the web-based Survey Monkey platform (SVMK, San Mateo, California, USA) was used to conduct the survey. The instrument was a dedicated perphysician, semiquantitative questionnaire (Appendix $1 \mathrm{~s}$, available online-only in Supplementary material). Data on individual patients were not collected; only intervals or ranges were reported for quantitative or numerical variables. The questionnaire items were organized into the following four domains of interest:

1. Section A (questions Q1-Q15) evaluated demographic and professional characteristics of participating physicians;

2. Section B (questions Q16-Q32) assessed participant adherence to the ESGE Technical Guideline [7];

3. Section C (questions Q33-Q43) assessed participant adherence to the ESGE Clinical Guideline [3];

4. Section D (questions Q44-Q52) assessed the physician's perspectives regarding the present and future of SBCE.

The final survey version was reviewed and authorized for multicenter distribution after pilot testing among authors and their collaborators.

\section{Survey distribution and collection of data}

The electronic version of the survey was disseminated to endoscopists via email accounts stored in the ESGE communication database. Each endoscopist received an email invitation twice (July and September 2019), including a link to the survey and an explanation of the purpose of the study. To prevent data duplication, only a single answered questionnaire per user was allowed by the electronic survey program. All information provided per user was automatically recorded anonymously into a software database (Microsoft Excel; Microsoft, Redmond, Washington, USA).

Acceptance of participation in the survey was considered to be a provision of consent for the collection and use of data for scientific purposes. The protocol of this survey was approved by the ESGE Research Committee Small-Bowel Working Group. Ethics committee approval was not obtained, since this study involved no sharing of patient data. 


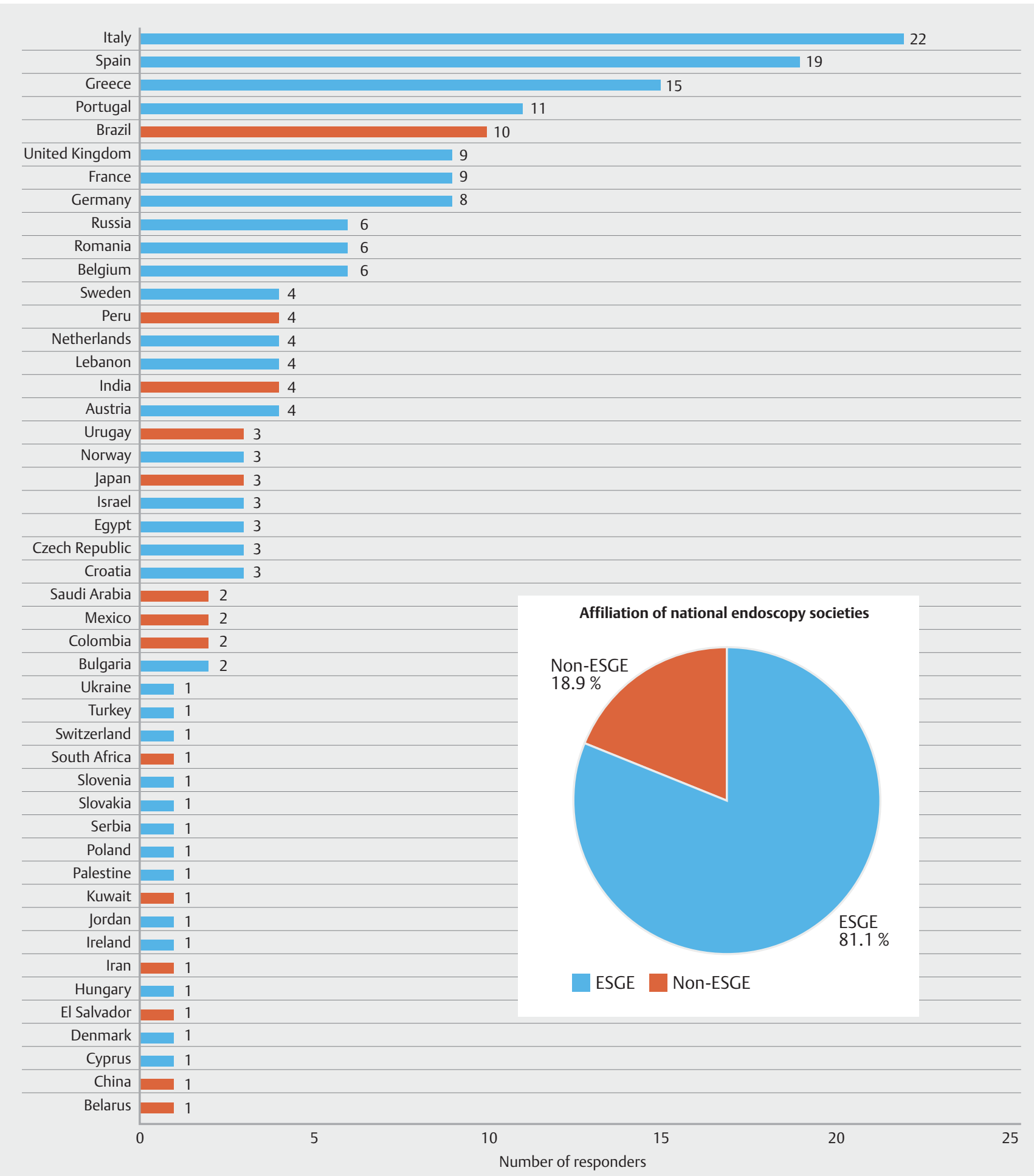

- Fig. 1 Geographical distribution of respondents to European Society of Gastrointestinal Endoscopy (ESGE) survey on small-bowel capsule endoscopy (SBCE).

\section{Study endpoints}

The primary endpoint was to document endoscopist adherence to current ESGE technical [7] and clinical [3] recommendations. The secondary endpoint was an assessment of endoscopists' perspectives regarding the present and future of SBCE in clinical practice. 


\section{Statistical analysis}

Quantitative data were expressed as mean and SD and categorical data as number and percentage. The normality of the distribution of quantitative data was assessed using the KolmogorovSmirnov statistic. Student's $t$ test was used to compare normally distributed variables, while nonparametric tests were used to analyze categorical and noncontinuous quantitative variables. All calculations were performed using the software statistical program Statistical Packages for Social Sciences (SPSS) version 25.0 (Chicago, Illinois, USA), with a $P$ value of $<0.05$ considered to be significant for all statistical assessments.

\section{Results}

\section{Respondent characteristics}

In total, 217 respondents from 47 countries completed the survey, with $81.1 \%$ and $18.9 \%$ originating from ESGE and nonESGE countries, respectively ( $\vee$ Fig. 1 ). Respondents had practiced SBCE for a mean of 8.6 years, the majority $(84.7 \%$ ) within a hospital environment, and with three quarters of them declaring that they followed the specific ESGE guidelines in their SBCE practice. The number of SBCEs performed by respondents showed no significant change over the 3 previous years (mean [SD], 52.7 [64.6], 55.4 [67.8], and 51.9 [71.5]; $P>0.49$ ). Respondents' characteristics are shown in $>$ Table 1.

\section{Study endpoints}

\section{Primary endpoint}

The main indications for SBCE in the current practice of respondents were obscure gastrointestinal bleeding (OGIB; $44.4 \%$ of cases), iron-deficiency anemia (29.2\%) and suspected or established Crohn's disease (CD) (18.1\%), a case mix that had remained stable over the past 5 years ( $\nabla$ Fig. $2 a$ ). Evaluation of OGIB and established CD were associated with the higher rates of positive findings, at $49.4 \%$ and $53.5 \%$, respectively ( $\mathbf{F i g}$. 2b). Positive findings were rarely detected when chronic diarrhea and abdominal pain were being evaluated $(15.1 \%$ and $11.9 \%$, respectively). The majority of responders stated that the rate of positive studies per indication had not changed over the years.

- Fig. 3 and > Table 2 illustrate respondents' adherence to ESGE technical recommendations [7]. Of the studies, $91 \%$ were performed for an appropriate indication. Most respondents (76.3\%) provided patients with verbal and written information, mainly about indications (84\%), contraindications (70.8\%), risk of retention (93.6\%), and the need for bowel preparation (78\%). A clear liquids diet (62.3\%) along with purgatives (85.4\%) and simethicone administration (73.2\%) was favored by most respondents, while $56.1 \%$ never gave prokinetics.

Regarding intraprocedural practices, in total $73.2 \%$ used real-time viewing: always in $38.4 \%$ or only in suspected prolonged gastric time in $34.8 \%$. Of the respondents, $86.7 \%$ reported not using a validated scale for bowel preparation qualification (but $54.2 \%$ provided a rough estimate of adequate/ inadequate preparation).
- Table 1 Characteristics of respondents to survey on adherence to European Society of Gastrointestinal Endoscopy (ESGE) guidelines for small-bowel capsule endoscopy (SBCE).

\section{SBCE setting (189 responses), $\mathbf{n}$ (\%)}

- Public hospital $133(70.4)$

- Private practice $29(15.3)$

- Private hospital $27(14.3)$

Patients receiving SBCE (192 responses), $\mathrm{n}$ (\%)

\begin{tabular}{l|l} 
- Adults $144(75.0)$ \\
\hline
\end{tabular}

" Both $46(24.0)$

- Children $2(1.00)$

Years of SBCE performance, mean (SD), years $8.6(3.6)$

Formal SBCE training for (191 responses), $\mathrm{n}$ (\%)

- No $105(55.0)$

- Yes $86(45.0)$

SBCE reimbursement (192 responses), $\mathrm{n}$ (\%)

\begin{tabular}{ll} 
- Always $83(43.2)$ \\
\hline
\end{tabular}

- Never $55(28.7)$

$54(28.1)$

- In selected indications

Studies per respondent, preceding 3 years, mean (SD), n (\%)

- $2016 \quad 52.7(64.6)$

- $2017 \quad 55.4(67.8)$

- $2018 \quad 51.9(71.5)$

Guideline used in everyday clinical practice (154 responses), n (\%)

- ESGE $102(66.2)$

- Local $27(17.6)$

- ASGE $14(9.0)$

- None $8(5.2)$

- Other $3(2.00)$

ASGE, American Society for Gastrointestinal Endoscopy

The majority of respondents read and interpreted the studies themselves (66.9\%). Studies were most often read either on single (47.5\%) or dual (44.2\%) view. Lesions were being located using the viewing software in only $15.8 \%$ of cases, while the rest provided an estimate or recorded the time lapse between a landmark and the lesion. Most respondents delivered the capsule endoscopically into the duodenum in patients with nonobstructive swallowing disorders (65.7\%) and performed SBCE without any restriction in patients with pacemakers $(62.5 \%)$. Roughly half of them (51.2\%) used a patency capsule in cases where small-bowel stenosis was suspected. Most responders (84.1\%) classified findings as "relevant" or "irrelevant." The essential components of an SBCE report were considered to be quality of mucosa visualization (90\%), and description, loca- 
- Table 2 Respondents' adherence to ESGE technical recommendations for small-bowel capsule endoscopy (SBCE). (See also $>$ Fig. 3.)

\begin{tabular}{|l|l|}
\hline Question and provided responses & $\%$ of re- \\
spon- \\
dents
\end{tabular}

29 Do you measure the quality of small bowel mucosa visualization, in your practice?

- I don’t measure it, but I just give an estimation e. g.

54.2 adequate vs. inadequate

- I don't measure it, I just report bad visualization 32.5 when appropriate

- I use an incremental scale for the whole SB 7.5

- I use an incremental scale for different segments of the recording separately

- I use a different measurement

30 How do you interpret the SBCE study findings in your practice?

- I classify findings as relevant, irrelevant or no findings

84.1

- I do not interpret, I only describe e. g. by using a recognized grading system such as Saurin for AVMs

- Other 1.6

31 Which of the following are essential components of the SBCE report in your opinion? Please select all that apply*

\begin{tabular}{|l|l|}
\hline - Description of the findings & 93.4 \\
\hline - Location of the findings & 90.8 \\
\hline - Quality of small-bowel mucosa visualization & 90.0 \\
\hline - Interpretation of the findings & 85.8 \\
\hline - Representative pictures & 81.7 \\
\hline - Transit times & 79.7 \\
\hline - Information regarding the completion of the exam & 70.6 \\
\hline - Information about the management of capsule & 47.5 \\
\hline \begin{tabular}{l} 
- Otention \\
\hline
\end{tabular}
\end{tabular}

32 Which aspects of your capsule endoscopy practice do you audit? Please indicate all which apply*

\begin{tabular}{|l|c|}
\hline - Overall diagnostic yield & 45.4 \\
\hline - Completion rate & 45.4 \\
\hline - Complication rate & 44.5 \\
\hline - Diagnostic yield per indication & 37.5 \\
\hline - Mucosal visualization & 32.8 \\
\hline - None & 29.4 \\
\hline - Other & 2.8 \\
\hline $\begin{array}{l}\text { AVM, arteriovenous malformation. } \\
\text { * Sum is greater than 100\% because of multiple possible answers for the } \\
\text { question. }\end{array}$
\end{tabular}

tion, and interpretation of the findings $(93.4 \%, 90.8 \%$, and $85.8 \%$, respectively). The aspects most frequently audited by the participants were the overall diagnostic yield $(45.4 \%)$, the completion rate $(45.4 \%$ and the complication rate ( $44.5 \%)$.

- Table 3 shows respondents' adherence to ESGE clinical guidelines [3]. Use of emergency SBCE in cases with OGIB was recommended by $67.4 \%$ of the respondents, to indicate the route of device-assisted enteroscopy $(34.1 \%)$ or to reveal the site of bleeding for further intervention (33.3\%). After a negative SBCE in small-bowel bleeding or iron-deficiency anemia, $46.7 \%$ and $70.3 \%$, respectively, preferred a watchful waiting strategy. SBCE was the second most frequently preferred second-line exam for CD evaluation (14.8\%), with computed tomography/magnetic resonance imaging enterography being the most frequently preferred (55.5\%). SCBE's limited role was seen as, for example, the evaluation of disease extent in newly diagnosed patients (62.2\%) and mucosal healing assessment in established CD (54.3\%).

Only a minority of practices (44.5\%) consistently measured a CD activity index at SBCE; in those cases, the Lewis score was most frequently used (39.1\%). Among the respondents $62.9 \%$ felt they could discriminate CD ulcerations from those of other etiology depending on the study indication, with serpiginous (53.3\%) or longitudinal character (41\%) and multiplicity of lesions $(41.3 \%)$ being considered the main characteristics of CD ulcers. The PillCam Crohn's capsule (Medtronic, USA) was mainly used for diagnostic panendoscopy in clinical practice (40.2\%), while some practitioners (22.8\%) used it for mucosal healing assessment.

Most respondents $(81.9 \%)$ did not consider SBCE as a firstline examination for the diagnosis of celiac disease, and $37.8 \%$ would consider performing the exam only in cases with strong suspicion of the disease and negative histology. The majority (58.3\%) claimed that SBCE might have a role in refractory celiac disease evaluation.

Respondents' adherence to ESGE guidelines was associated neither with local endoscopy setting (hospital-based vs. officebased) nor with national society affiliation (ESGE vs. non-ESGE) ( $\triangleright$ Table 4). Endoscopists with formal SBCE training (45\% of respondents) showed numerically higher percentages of adherence to all ESGE recommendations; however statistical significance was reached only for use of antifoaming agents $(50.8 \%$ vs. $28.4 \%, P=0.008$ ) and proper interpretation of study findings (relevant, irrelevant, or no findings; $92.3 \%$ vs. $76.9 \%, P=0.02$ ).

\section{Secondary endpoint}

Endoscopists' perspectives regarding the present and future role of SBCE are presented in > Table 5 . While $61.4 \%$ of the practitioners had noticed a definite or possible increase in demand for SBCE, only $7.6 \%$ had noticed a decrease in demand. The majority of respondents (67.6\%) anticipated an increase in the demand for SBCE over the next 5 years and $64.5 \%$ of them expected that the examination would continue to evolve. Most respondents did not foresee any significant changes in the current indications in the future, and $51.1 \%$ wished to extend SBCE indications to unexplained iron deficiency without anemia. The inability to perform biopsies and targeted treatment (78.3\%), 


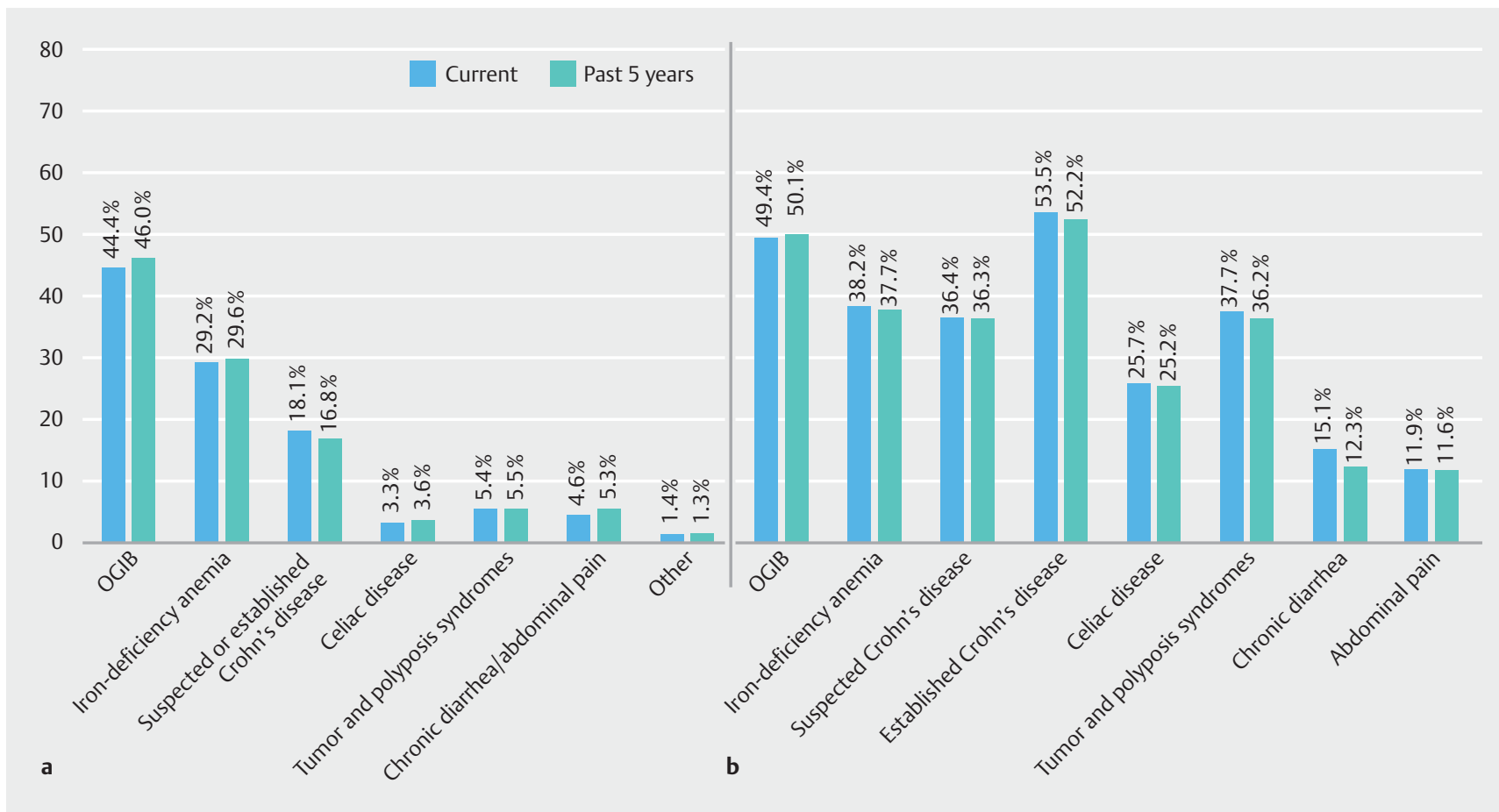

- Fig. 2a Indications rates for SBCE procedures for current and past 5 years. No statistically significant differences were detected. b Rates of procedures with positive findings during the same periods. No statistically significant differences were detected. OGIB, obscure gastrointestinal bleeding.

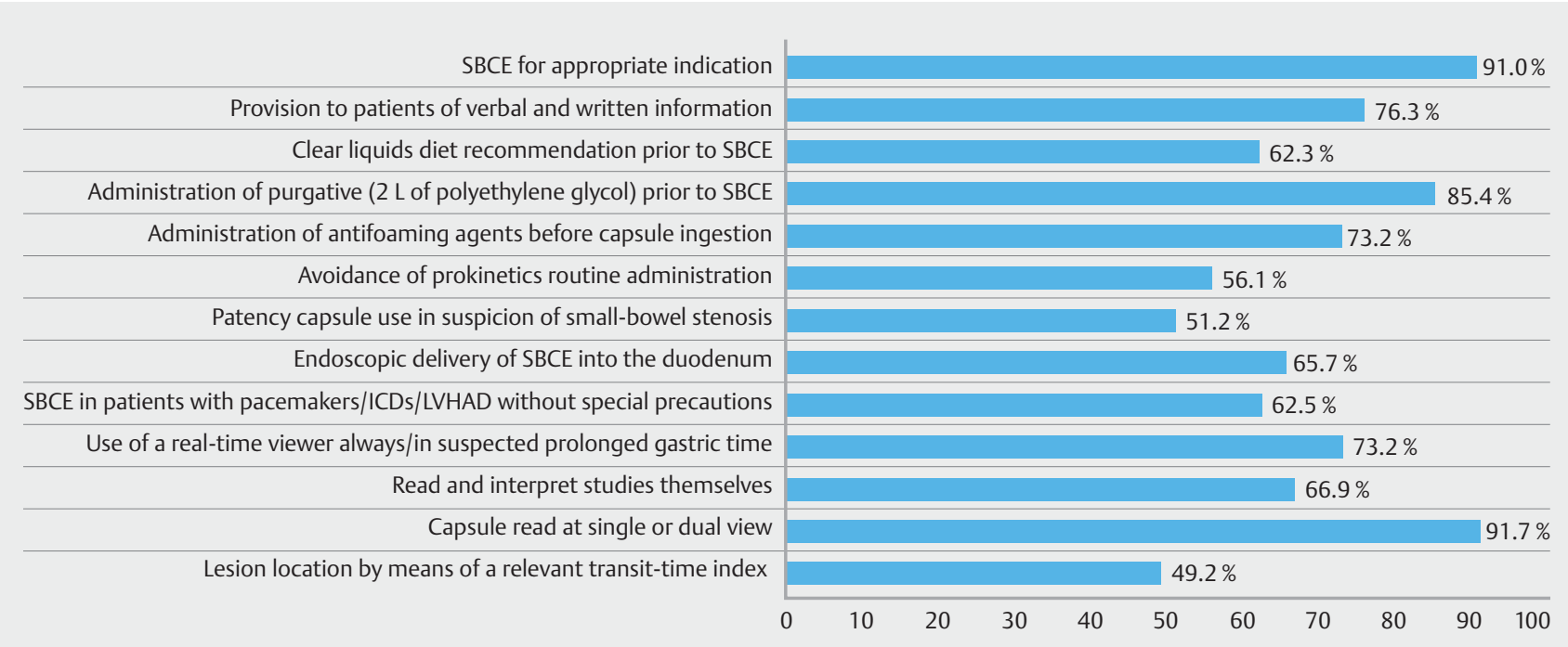

- Fig. 3 Respondents' adherence to ESGE technical recommendations for small-bowel capsule endoscopy (SBCE) (see also > Table 2). ICD, implantable cardioverter defibrillator; LVHAD, left ventricular heart assist device.

the cost of the exam (68.1\%), and the time burden for reading and interpreting the study (64.7\%) were deemed the principal drawbacks of the procedure. Automated reading using artificial intelligence ( $\mathrm{Al}$ ) algorithms (56.2\%) and therapeutic ability (39.7\%) were considered as areas for future development.

\section{Discussion}

The current web-based survey represents the first international attempt to obtain a comprehensive picture regarding adherence to ESGE clinical, technical, and procedural guidelines for SBCE by capturing data from facilities in ESGE and non-ESGE countries. 
- Table 3 Respondents' adherence to ESGE clinical recommendations for SBCE.

\section{Question and provided responses}

$\%$ of respondents

33 What is the main role of emergency (during $24 \mathrm{~h}$ ) SBCE during active, severe OGIB (obscure gastrointestinal bleeding) in your practice?

- To indicate the route of device-assisted enteroscopy 34.1

- To indicate the site of bleeding for other interven- 33.3 tion (radiological, surgical)

- None

30.4

- Other

2.2

34 How do you manage your small-bowel bleeding patient after negative SBCE?

- Watchful waiting

- Radiology evaluation 46.7

- Repeat upper and lower Gl endoscopy

- Repeat upper lower Gl endoscopy and SBCE

- Other (please specify)

14.6

5.9

5.8

35 How do you manage your iron-deficiency anemia patient after negative SBCE?

\begin{tabular}{|l|l|}
\hline - Watchful waiting & 70.3 \\
\hline - Radiology evaluation & 10.9 \\
\hline - Repeat upper and lower Gl endoscopy & 10.1 \\
\hline - Other (please specify) & 5.8 \\
\hline - Repeat upper lower Gl endoscopy and SBCE & 2.9 \\
\hline
\end{tabular}

36 Which is the next examination that you recommend following a new diagnosis of Crohn's disease with ileo-colonoscopy and biopsy?

- CTor MR enterography 55.5

\begin{tabular}{l|l} 
- SBCE & 14.8 \\
\hline
\end{tabular}

- None 9.4

- Gastroduodenoscopy and biopsy $\quad 8.6$

- Abdominal CT or MRI 7.8

- Other (please specify)

37 What is the role of SBCE in newly diagnosed Crohn's disease in your practice? (multiple answers are allowed)*
- Evaluation of disease extension
62.2
- Treatment modification
- Evaluation of disease activity
41.0
38.6
- Treatment monitoring
30.2
- None
- Other (please specify)

38 What is the role of SBCE in established Crohn's disease in your practice? (multiple answers are allowed) *
- Mucosal healing assessment
54.3

- Treatment monitoring
- Table 3 (Continuation)

\section{Question and provided responses}

$\%$ of respondents

- None

- Other (please specify)

2.4

39 Do you use SBCE Crohn's disease activity indices in your practice?

\begin{tabular}{|l|l}
\hline - Always & 44.5 \\
\hline - Never & 43.0 \\
\hline - Sometimes (please specify) & 12.5
\end{tabular}

40 Which SBCE activity index score do you use in your practice?

- None

- Lewis score

- CECDAl (or Niv score)

41 When interpreting SBCE videos, can you tell that detected ulceration are due to Crohn's disease?

- Sometimes, depends on study indication

- Sometimes depending on another discriminating

15.3 reason (please outline)

- Always

8.1

- Never

7.2

- Sometimes, depends on patient's demographics

6.5

42 What characteristics of Crohn's disease ulcers at SBCE differentiate them from NSAIDs lesions? Please indicate all which apply*

\begin{tabular}{|l|c|}
\hline - Serpiginous lesions & 53.3 \\
\hline - Multiple lesions & 41.3 \\
\hline - Longitudinal lesions & 41.0 \\
\hline $\begin{array}{l}\text { - Ulcerations associated with edema of the sur- } \\
\text { rounding mucosa }\end{array}$ & 38.5 \\
\hline - Confluent lesions & 31.4 \\
\hline - Lesion extending beyond two folds & 25.4 \\
\hline - None & 19.8 \\
\hline - Lesions evolving only in a certain part of the small & 16.5 \\
\hline $\begin{array}{l}\text { - Lowel } \\
\text { iphery }\end{array}$ & 8.2 \\
\hline - Other (please specify) & 7.3 \\
\hline - Clean ulcer base & 4.1 \\
\hline
\end{tabular}

43 In your opinion, what will be the positioning of the new PillCam Crohn's in clinical practice

- Diagnostic panendoscopy

40.2

- Mucosal healing assessment

22.8

- Treatment monitoring

18.9

- No diagnostic gap to fill

12.6

- Other (please specify)

5.5 
- Table 3 (Continuation)

\begin{tabular}{|l|l|}
\hline Question and provided responses & $\begin{array}{l}\% \text { of re- } \\
\text { spondents }\end{array}$ \\
\hline
\end{tabular}

44 What is the main role of SBCE for the diagnosis of celiac disease, in your practice?

\begin{tabular}{|l|c|}
\hline - None & 44.1 \\
\hline \begin{tabular}{l|l} 
- In cases with strong suspicion (e. g. positive antibo- \\
dies) and negative histology
\end{tabular} & 37.8 \\
\hline - Evaluate disease extension & 11.8 \\
\hline - Other (please specify) & 6.3 \\
\hline
\end{tabular}

45 What is the main role of SBCE for the management of established celiac disease, in your practice?

- Refractory disease evaluation

- None 31.5

- Treatment monitoring 7.9

- Other (please specify) 2.3

$\mathrm{Gl}$, gastrointestinal; CT, computed tomography; MRI, magnetic resonance imaging; CECDAI, Capsule Endoscopy Crohn's Disease Activity Index; NSAID, nonsteroidal anti-inflammatory drug.

* Sum is greater than $100 \%$ because of multiple possible answers for the question.

Quality improvement programs are the optimal way to ensure the provision of high quality, cost-effective healthcare services. They help to standardize performance of procedures, reducing intraobserver variability and maximizing the effectiveness of the process itself. In this regard, quality improvement programs have been widely implemented in Gl endoscopy, covering several techniques including upper and lower GI endoscopy $[12,13]$. Although SBCE was introduced more than two decades ago, it is only very recently that quality indices for the procedure have been published [6].

The fundamental requirement for each quality improvement program remains the collection and processing of data that reflect the performance of individual endoscopists in an everyday clinical setting [14]. Nonetheless, fulfilment of this requirement has been proven to be somewhat inexact, given the relative scarcity of data on SCBE delivery. The first study, which "scratched the surface," took place in the UK 10 years ago [8, 9]; the authors documented the local demands for SBCE and evaluated the potential impact of formal training on the procedure outcomes, but no data on practical topics and procedure protocols were collected. Later, two studies with similar aims were published $[15,16]$, but both had remained within national borders, and did not provide a structured assessment of the issues mentioned above. Hence, the study by Rondonotti et al. [10] pioneered the collection of data on technical and procedural issues in a systematic and organized manner. Still, the evidence collected reflected only SBCE practices in Italy, and therefore the applicability of these results to other national settings remained questionable.

Considering the inherent differences geographically or in healthcare systems, the considerable variability in patient man- agement, the number of participating centers, and lack of uniform clinical characteristics of the participants, direct comparisons with our results are problematic. Although these particular types of studies may suffer from inherent flaws, at the same time, they nevertheless represent an indicator of progress in each quality improvement program. Perhaps even more valuable is their role in "bridging the gap" between guidelines and their practical incorporation into everyday clinical practice (that is, supporting evidence-based medicine), through taking into consideration the local setting, as well as overcoming the practice behavior of individual doctors and patient skepticism towards the optimal medical care for their clinical condition [17].

Our study is the first to present interesting user observations regarding the present and future role of SBCE. Although we have documented that the number of procedures has remained stable over the years, the largest proportion of respondents anticipated a definite increase in demand while the procedure is bound to evolve. This is despite the advent of novel, sophisticated diagnostic modalities competing with SCBE: the examination's high diagnostic yield, the excellent patient safety profile, and the considerable amount of scientific data available that further optimize its performance in various settings, may potentially explain these findings [18]. This might also be a result of endoscopist maturation; participants have not only achieved competence in interpretation of study findings and post-procedure clinical management of patients, but have further optimized SBCE use by following established clinical practice recommendations for all the other significant yet underrated pre- and post-procedure domains [10]. In fact, this might be the case, since data show that the accumulated experience of clinical practice has led to standardization of the integral features of the procedure, e. $g$. the indication $[3,16]$.

The survey findings further corroborate that the largest proportion of respondents perform SBCE for an appropriate indication, minimizing exposure to procedure-related complications and enhancing SCBE diagnostic yield and patient outcomes [19]. In addition, participants expressed the belief that the indication case mix will remain unaltered at present but might potentially be extended to include unexplained iron deficiency without anemia. SBCE holds a pivotal role in the OGIB/irondeficiency anemia investigation algorithm, while in the case of $C D$, it allows accurate visualization of the small bowel with a high diagnostic yield that even surpasses that of other imaging modalities [3, 20,21]. Taken together, these data suggest that, after all these years, the examination has established itself in the minds of clinicians as the superior first-line diagnostic option for investigation of patients. On the other hand, respondents recognise the potential role of SBCE for other indications, where its usefulness is at present debatable, e.g. celiac disease [3]. Obviously, the inability to perform tissue acquisition, tattooing, and targeted treatment still represent the main drawbacks of the procedure, while upcoming artificial intelligence systems promise to improve lesion detection and characterization [22].

The majority of respondents (from ESGE and non-ESGE countries) were found to adhere to ESGE guidelines in practice; they informed patients about the merits and potential pitfalls of the procedure, administered purgatives along with a clear 
- Table 4 Comparison of individuals' adherence to European Society of Gastrointestinal Endoscopy (ESGE) technical guidelines, according to endoscopy setting (hospital-based vs. office-based), history of formal small-bowel capsule endoscopy (SBCE) training and national endoscopic society affiliation (ESGE vs. non-ESGE).

\begin{tabular}{|c|c|c|c|c|c|c|c|c|c|c|}
\hline & \multicolumn{4}{|c|}{ Local endoscopy setting } & \multicolumn{3}{|c|}{ Formal SBCE training } & \multicolumn{3}{|c|}{$\begin{array}{l}\text { National endoscopy society } \\
\text { affiliation }\end{array}$} \\
\hline & $\begin{array}{l}\text { Private } \\
\text { clinic }\end{array}$ & $\begin{array}{l}\text { Public } \\
\text { clinic }\end{array}$ & $\begin{array}{l}\text { Private } \\
\text { office }\end{array}$ & $\begin{array}{l}P \\
\text { values }\end{array}$ & No & Yes & $\begin{array}{l}P \\
\text { value }\end{array}$ & $\begin{array}{l}\text { Non- } \\
\text { ESGE }\end{array}$ & ESGE & $\begin{array}{l}P \\
\text { value }\end{array}$ \\
\hline \multicolumn{11}{|l|}{ Preprocedure } \\
\hline $\begin{array}{l}\text { Mode of information provid- } \\
\text { ed to patients }\end{array}$ & $65.0 \%$ & $80.4 \%$ & $75.0 \%$ & $\begin{array}{l}0.13^{1} \\
0.47^{2}\end{array}$ & $74.6 \%$ & $79.0 \%$ & 0.54 & $76.9 \%$ & $76.3 \%$ & 0.92 \\
\hline $\begin{array}{l}\text { Specific information provid- } \\
\text { ed to patients }\end{array}$ & $70.8 \%$ & $82.7 \%$ & $87.8 \%$ & $\begin{array}{l}0.19^{1} \\
0.14^{2}\end{array}$ & $73.3 \%$ & $79.3 \%$ & 0.13 & $87.8 \%$ & $83.8 \%$ & 0.53 \\
\hline Diet recommendation & $78.9 \%$ & $93.6 \%$ & $65.2 \%$ & $\begin{array}{l}0.06^{1} \\
0.33^{2}\end{array}$ & $58.1 \%$ & $68.8 \%$ & 0.23 & $70.8 \%$ & $59.6 \%$ & 0.3 \\
\hline $\begin{array}{l}\text { Small-bowel purgative } \\
\text { administration }\end{array}$ & $52.6 \%$ & $43.6 \%$ & $34.8 \%$ & $\begin{array}{l}0.47^{1} \\
0.24^{2}\end{array}$ & $42.2 \%$ & $47.5 \%$ & 0.55 & $33.3 \%$ & $46.0 \%$ & 0.24 \\
\hline Simethicone administration & $52.6 \%$ & $34.4 \%$ & $52.1 \%$ & $\begin{array}{l}0.13^{1} \\
0.97^{2}\end{array}$ & $28.4 \%$ & $50.8 \%$ & 0.008 & $50.0 \%$ & $36.8 \%$ & 0.23 \\
\hline Avoidance of prokinetics & $36.8 \%$ & $61.2 \%$ & $43.4 \%$ & $\begin{array}{l}0.06^{1} \\
0.66^{2}\end{array}$ & $40.8 \%$ & $49.1 \%$ & 0.18 & $45.8 \%$ & $57.8 \%$ & 0.28 \\
\hline Patency capsule use & $53.3 \%$ & $51.8 \%$ & $45.00 \%$ & $\begin{array}{l}0.91^{1} \\
0.63^{2}\end{array}$ & $51.5 \%$ & $52.9 \%$ & 0.96 & $38.8 \%$ & $53.3 \%$ & 0.25 \\
\hline $\begin{array}{l}\text { Endoscopic delivery into } \\
\text { duodenum }\end{array}$ & $40.1 \%$ & $58.5 \%$ & $35.0 \%$ & $\begin{array}{l}0.19^{1} \\
0.79^{2}\end{array}$ & $45.4 \%$ & $50.2 \%$ & 0.62 & $44.4 \%$ & $54.3 \%$ & 0.43 \\
\hline $\begin{array}{l}\text { Use in patients with pace- } \\
\text { makers/ICDs/LVHAD }\end{array}$ & $53.3 \%$ & $65.8 \%$ & $50.2 \%$ & $\begin{array}{l}0.34^{1} \\
0.86^{2}\end{array}$ & $60.6 \%$ & $63.4 \%$ & 0.75 & $47.1 \%$ & $65.0 \%$ & 0.15 \\
\hline \multicolumn{11}{|l|}{ Intraprocedure } \\
\hline Use of real-time viewing & $21.0 \%$ & $41.9 \%$ & $39.1 \%$ & $\begin{array}{l}0.08^{1} \\
0.21^{2}\end{array}$ & $37.7 \%$ & $45.9 \%$ & 0.36 & $41.6 \%$ & $37.7 \%$ & 0.72 \\
\hline \multicolumn{11}{|l|}{ Post-procedure } \\
\hline Reader of studies & $57.1 \%$ & $66.6 \%$ & $75.1 \%$ & $\begin{array}{l}0.49^{1} \\
0.27^{2}\end{array}$ & $64.0 \%$ & $69.2 \%$ & 0.55 & $55.5 \%$ & $69.0 \%$ & 0.72 \\
\hline Reading speed & $46.6 \%$ & $41.4 \%$ & $60.0 \%$ & $\begin{array}{l}0.70^{1} \\
0.43^{2}\end{array}$ & $48.4 \%$ & $61.5 \%$ & 0.15 & $58.8 \%$ & $41.7 \%$ & 0.19 \\
\hline $\begin{array}{l}\text { Small-bowel mucosa visuali- } \\
\text { zation quality assessment }\end{array}$ & $60.0 \%$ & $40.2 \%$ & $60.0 \%$ & $\begin{array}{l}0.15^{1} \\
1^{2}\end{array}$ & $51.5 \%$ & $59.6 \%$ & 0.8 & $50.0 \%$ & $54.9 \%$ & 0.7 \\
\hline Lesion location & $40.0 \%$ & $50.0 \%$ & $45.0 \%$ & $\begin{array}{l}0.47^{1} \\
0.77^{2}\end{array}$ & $48.2 \%$ & $48.0 \%$ & 0.97 & $58.8 \%$ & $47.5 \%$ & 0.38 \\
\hline $\begin{array}{l}\text { Activity index scores for } \\
\text { Crohn's disease }\end{array}$ & $61.2 \%$ & $44.1 \%$ & $38.1 \%$ & $\begin{array}{l}0.19^{1} \\
0.15^{2}\end{array}$ & $39.1 \%$ & $49.1 \%$ & 0.26 & $52.2 \%$ & $42.8 \%$ & 0.41 \\
\hline $\begin{array}{l}\text { Study findings interpreta- } \\
\text { tion }\end{array}$ & $86.6 \%$ & $82.7 \%$ & $90.0 \%$ & $\begin{array}{l}0.75^{1} \\
0.75^{2}\end{array}$ & $76.9 \%$ & $92.3 \%$ & 0.02 & $76.4 \%$ & $85.2 \%$ & 0.36 \\
\hline
\end{tabular}

liquids diet and antifoaming agents, and stated that the use of implantable cardiac devices did not preclude the examination [7]. A deviation from the guidelines was identified in the application of real-time monitoring, with the majority not doing this or implementing it only when prolonged gastric time was strongly suspected. This finding might result from clinical experience that supports the notion that the device will indeed advance to the duodenum within 4 hours in the vast majority of cases (97\%-100\%), arguing against the routine use of real-time 
- Table 5 Respondents' perspectives regarding the present and future role of SBCE.

\begin{tabular}{|l|l|}
\hline Question and provided responses & $\begin{array}{l}\text { \% of re- } \\
\text { sponders }\end{array}$
\end{tabular}

46 Have you noticed an increase or decrease in the demand for SBCE during the past five years?

\begin{tabular}{|l|l|}
\hline - Definite/possible increase in demand & 61.4 \\
\hline - Neither increase nor decrease in demand & 31.0 \\
\hline - Definite/possible decrease in demand & 7.6 \\
\hline
\end{tabular}

47 Do you anticipate an increase or decrease in demand for SBCE for the next five years?

\begin{tabular}{|l|c|}
\hline - Definite/possible increase in demand & 67.6 \\
\hline - Neither increase nor decrease in demand & 26.7 \\
\hline - Definite/possible decrease in demand & 5.7 \\
\hline 48 In your opinion, what is the future of SBCE in clinical practice? \\
\hline - Examination will continue to evolve & 64.5 \\
\hline - Examination has reached a plateau & 23.1 \\
\hline - Examination will be substituted by other modalities & 6.6 \\
\hline in the near future & \\
\hline - I don't know & 5.8 \\
\hline
\end{tabular}

49 Do you foresee a significant change in the SBCE indications case mix in the next five years?

$$
\text { - Will stay the same }
$$

- Will increase 36.3

- Will decrease

$\mathbf{5 0}$ In your opinion, should SBCE indications be extended to unexplained iron deficiency without anemia

\begin{tabular}{|l|l|}
\hline - Yes & 51.1 \\
\hline - No & 36.7 \\
\hline . Don't know & 12.2 \\
\hline
\end{tabular}

51 In your opinion, which of the following are for the disadvantages of SBCE? Please select all that apply*
- Inability to obtain biopsy, tattooing - targeted treatment
78.3

- Cost-reimbursement

68.1

- The time required to read and interpret the study

64.7

- Accurate findings localization

59.7

- Capsule external maneuverability

23.3

- Other (please specify)

0.8

$\mathbf{5 2}$ What is the top priority area for development?

- Automated reading using artificial intelligence al56.2 gorithms

- Therapeutic ability

- Additional ability (please specify)

* Sum is greater than $100 \%$ because of multiple possible answers for the question. viewing; nevertheless, appropriate real-time viewing is crucial since it has been associated with higher completion rates [23].

Another interesting finding from the survey is that most endoscopists involved in performing SBCE have not undergone any formal training. SBCE training programs are neither available nor a prerequisite for completing specialist gastroenterology training in most countries [24-26]. Still, their beneficial effect on lesion recognition and improvement in classification skills is undisputed [9]. Our results support the notion that formal training is associated with higher adherence to established guidelines, thus optimizing SBCE performance. In the light of these observations, the need for a core curriculum that would certify the acquisition of adequate knowledge and skill for a physician to provide an SBCE service of the highest quality is more pertinent than ever [27].

The strengths of this study include its novelty, since this is the first study to not only systematically document SBCE practice at a European level but also to evaluate respondents' adherence to ESGE technical and clinical guidelines. Secondly, the representativeness of our sample, collecting data from endoscopists in many different healthcare settings, increases the generalizability of the results.

On the other hand, some limitations merit attention. The main one relates to the study design, since this type is per se prone to recall and self-report biases. In addition, such a design does not allow collection of patient data; thus, it maps the attitude of participants towards guideline adherence rather than actual compliance. Moreover, we used a questionnaire designed according to existing literature rather than using a validated instrument. Finally, the lack of a specific number of preregistered SBCE endoscopists in the ESGE database prevented response rate calculation.

In summary, this multinational survey showed that endoscopists adhere to a certain degree to ESGE guidelines on the use of SBCE in clinical practice. Despite the guidelines' wide use and availability, some concordance gaps in technical and practical/ organizational issues related to SBCE use have also been identified. These findings could lead the way to further bridge the gap between current practice and guideline recommendations.

\section{Competing interests}

$X$. Dray is a co-founder of and shareholder in Augmented Endoscopy (from July 2019, ongoing); he has provided consultancy to Norgine (January to December 2020); he holds a patent for a device and method for classifying the quality of digestive capsule endoscopy image. R. Eliakim has provided consultancy to Medtronic (from 2016, ongoing). M. Keuchel has provided consultancy to and received speaker's fees from Medtronic; he has received a speaker's fee from Olympus; he is the co-editor of a book on capsule endoscopy. A. Koulaouzidis is a consultant for Jinshan (from March 2021, ongoing); he is a co-director of iCERV (from June 2020, ongoing); he is a co-founder of and a stakeholder in AJM Medicaps (from March 2021, ongoing). S. Panter has provided consultancy for and has received support for research projects from Medtronic. E. Rondonotti has received speaker honoraria from Fujifilm. B. Rosa has provided consultancy for and has received sponsorship from Medtronic (from 2020, ongoing). C. Spada has provided consultancy to Medtronic (from 2017 to 2021). E. Toth has provided consultancy to and received a lecture fee from Medtronic 
(2017 to 2021) and Norgine 2018 to 2021). H. Beaumont, P. Bhandari, P. Ellul, I. Fernandez-Urien, R. Jover, L.-D. Lazaridis, K. Triantafyllou, and $\mathrm{G}$. Tziatzios, declare no competing interests.

References

[1] Koulaouzidis A, Rondonotti E, Karargyris A. Small-bowel capsule endoscopy: a ten-point contemporary review. World J Gastroenterol 2013; 19: 3726-3746

[2] Tziatzios G, Gkolfakis P, Dimitriadis GD et al. Long-term effects of video capsule endoscopy in the management of obscure gastrointestinal bleeding. Ann Transl Med 2017; 5: 196

[3] Pennazio M, Spada C, Eliakim R et al. Small-bowel capsule endoscopy and device-assisted enteroscopy for diagnosis and treatment of small-bowel disorders: European Society of Gastrointestinal Endoscopy (ESGE) Clinical Guideline. Endoscopy 2015; 47: 352-376

[4] Gerson LB, Fidler JL, Cave DR et al. ACG Clinical Guideline: Diagnosis and management of small bowel bleeding. Am J Gastroenterol 2015; 110: 1265-1287; quiz 1288

[5] Yung DE, Rondonotti E, Giannakou A et al. Capsule endoscopy in young patients with iron deficiency anaemia and negative bidirectional gastrointestinal endoscopy. United European Gastroenterol J 2017; 5: 974-981

[6] Spada C, McNamara D, Despott E] et al. Performance measures for small-bowel endoscopy: a European Society of Gastrointestinal Endoscopy (ESGE) Quality Improvement Initiative. Endoscopy 2019; 51: $574-598$

[7] Rondonotti E, Spada C, Adler S et al. Small-bowel capsule endoscopy and device-assisted enteroscopy for diagnosis and treatment of small-bowel disorders: European Society of Gastrointestinal Endoscopy (ESGE) Technical Review. Endoscopy 2018; 50: 423-446

[8] McAlindon ME, Parker CE, Hendy P et al. Provision of service and training for small bowel endoscopy in the UK. Frontline Gastroenterol 2012; 3: 98-103

[9] Hale MF, Davison C, Panter S et al. Practical aspects of delivering a small bowel endoscopy service in the UK. Frontline Gastroenterol 2015; 6: 132-140

[10] Rondonotti E, Spada C, Pennazio M et al. Adherence to European Society of Gastrointestinal Endoscopy recommendations of endoscopists performing small bowel capsule endoscopy in Italy. Dig Liver Dis 2019; $51: 818-823$

[11] Rondonotti E, Spada C, Cadoni S et al. Quality performance measures for small capsule endoscopy: Are the ESGE quality standards met? Endosc Int Open 2021; 9: E122-E129

[12] Bisschops R, Areia M, Coron E et al. Performance measures for upper gastrointestinal endoscopy: a European Society of Gastrointestinal Endoscopy (ESGE) Quality Improvement Initiative. Endoscopy 2016; 48: 843-864
[13] Kaminski MF, Thomas-Gibson S, Bugajski M et al. Performance measures for lower gastrointestinal endoscopy: a European Society of Gastrointestinal Endoscopy (ESGE) Quality Improvement Initiative. Endoscopy 2017; 49: 378-397

[14] Conte D, Triantafyllou K. Small bowel capsule endoscopy: It's time for quality assurance. Dig Liver Dis 2019; 51: 824-825

[15] Rosa B. Capsule endoscopy in Portugal. Ann Transl Med 2017; 5: 200

[16] Triantafyllou K, Gkolfakis P, Viazis N et al. A 13-year time trend analysis of 3724 small bowel video capsule endoscopies and a forecast model during the financial crisis in Greece. Eur J Gastroenterol Hepatol 2017; 29: 185-191

[17] Woolf SH, Grol R, Hutchinson A et al. Clinical guidelines: potential benefits, limitations, and harms of clinical guidelines. BMJ 1999; 318: 527-530

[18] Chetcuti Zammit S, Sidhu R. Capsule endoscopy - Recent developments and future directions. Expert Rev Gastroenterol Hepatol 2021; 15: $127-137$

[19] Liao Z, Gao R, Xu C et al. Indications and detection, completion, and retention rates of small-bowel capsule endoscopy: a systematic review. Gastrointest Endosc 2010; 71: 280-286

[20] Riccioni ME, Urgesi R, Spada C et al. Unexplained iron deficiency anaemia: Is it worthwhile to perform capsule endoscopy? Dig Liver Dis 2010; 42: 560-566

[21] Dionisio PM, Gurudu SR, Leighton JA et al. Capsule endoscopy has a significantly higher diagnostic yield in patients with suspected and established small-bowel Crohn's disease: a meta-analysis. Am J Gastroenterol 2010; 105: 1240-1248; quiz 1249

[22] Postgate A, Haycock A, Thomas-Gibson S et al. Computer-aided learning in capsule endoscopy leads to improvement in lesion recognition ability. Gastrointest Endosc 2009; 70: 310-316

[23] Hosono K, Endo H, Sakai E et al. Optimal approach for small bowe capsule endoscopy using polyethylene glycol and metoclopramide with the assistance of a real-time viewer. Digestion 2011; 84: 119125

[24] Sidhu R, McAlindon ME, Davison C et al. Training in capsule endoscopy: are we lagging behind? Gastroenterol Res Pract 2012; 2012: 175248

[25] Fernandez-Urien I, Panter S, Carretero C et al. International core curriculum for capsule endoscopy training courses. Endosc Int Open 2017; 5: E526-E538

[26] Koffas A, Laskaratos FM, Epstein O. Training in video capsule endoscopy: Current status and unmet needs. World J Gastrointest Endosc 2019; 11: 395-402

[27] Sidhu R, Chetcuti Zammit S, Baltes P et al. Curriculum for small-bowel capsule endoscopy and device-assisted enteroscopy training in Europe: European Society of Gastrointestinal Endoscopy (ESGE) Position Statement. Endoscopy 2020; 52: 669-686 